\title{
Vision Zero from the Perspective of Traffic Psychology
}

\author{
M. Šucha* \\ Department of Psychology, Faculty of Arts, Palacky University in Olomouc \\ * Corresponding author: matus.sucha@upol.cz
}

DOI: 10.2478/v10158-012-0048-6

\begin{abstract}
The presented article reflects a scientific approach to the concept of a traffic system known as Vision Zero, which was postulated in 1997 by prof. Kare Rumar in Sweden. The implications of this approach are explored in terms of psychology. Other documents of the European Commission (including "Towards a European Road Safety Area: policy orientations on road safety 2011-2020") and the development of traffic safety in the Czech Republic are also discussed. The article seeks to provide information about the vision of traffic safety in European countries, which is based on the tenet that each road fatality is unnecessary - "Vision Zero". Attention is focused on the period 2012-2020, trends pursued by the European Union in this area, and the practical implications of such efforts for the Czech Republic, with a view to specific implementation measures. Drawing on their experience, the authors point out the existence of fragmentary and inconsistent approaches to the issue of road safety in the Czech Republic, specifically at the level of practical application (assessment in terms of traffic psychology, driver recruitment, prevention, training, law enforcement, rehabilitation, etc.), where organisations and/or individuals carry out measures which are not beneficial to road traffic safety, or there is no evidence of their contribution to road safety. The roles of psychology, traffic psychology, and traffic psychologists in designing the traffic system inspired by Vision Zero are underlined. The article provides a general background to the topic of traffic safety and the measures that can be adopted to improve it.
\end{abstract}

KEY WORDS: Vision zero, traffic system, traffic safety, traffic psychology.

\section{INTRODUCTION}

Out of all human-machine systems used on a daily basis, the road traffic system is the least forgiving; the human factor is reportedly responsible for over $90 \%$ of failures within the system. A traffic accident is far from being a totally accidental event: coincidence is involved to a lesser degree than human error. Accidents result from the synergetic adverse effects of several factors (including people, vehicles, road, its surroundings, and traffic conditions), with the human factor playing the crucial role. In comparison to the road transportation system, other well-established systems that have developed over longer periods are characterised by very strong, even insurmountable, tolerance for human failure (Johansson, 1991). One could say that if introduced today, road traffic would have to be banned immediately according to the current safety regulations. While health and safety risks in many areas of public life have been reduced dramatically in the past 100 years, this has not been the case with road transport. With a hint of exaggeration, the road traffic system may be referred to as a "historical relic" in this respect. In people's everyday 
activities, there is hardly any undertaking as dangerous as participating in the road traffic system. Moreover, roads become the sites of illegal activities and crime, including those not specifically related to traffic, more often than any other public areas. Traffic operations thus give rise to a massive number of criminal offences and impose a disproportionately heavy burden on the criminal justice system (Sheller \& Urry, 2006). As a result of the low tolerance for error within the road traffic system, in the Czech Republic there are annually 700 fatal road accidents and 25.000 people are injured, with 3.000 of them being left disabled. In other words, it has been a rule for years that an average of two people are killed every day and over 70 are injured, including 10 left with permanent health consequences. These injuries reduce life expectancy by at least 6 months and cause an average loss of 2.5 healthy life years per citizen. Many people's lives are affected by pain, limited mobility, and impaired mental capacity.

\section{OVERVIEW OF GENERAL EU DOCUMENTS WITH RELEVANCE TO VISION ZERO}

While the European Commission's $3^{\text {rd }}$ European Road Safety Action Programme 2003-2010 (European Commission, 2010) led to a considerable decline in the number of road fatalities and injuries, it fell short of the ambitious objective of reducing the number of road trafficrelated deaths within the European Union by half by 2010 .

This goal has been set again in the new road safety action plan for the period 2011-2020. According to the EC's document "Towards a European Road Safety Area: policy orientations on road safety 2011-2020" (European Commission, 2010), the road user is the first link in the road safety chain. Whatever the technical measures in place, the effectiveness of a road safety policy depends ultimately on road users' behaviour. For this reason, education, training, and enforcement are essential. However, the road safety system also has to take into account human error and inappropriate behaviour and correct it as much as possible zero risk does not exist. All its components, in particular vehicles and infrastructure, should therefore be "forgiving", so as to prevent and limit the consequences of these failures for the users, in particular the most vulnerable ones.

The document further sets out the following strategic objectives:

- Improving the education and training of road users (the "educational continuum" continuous training for non-professional drivers, education of professional drivers, driving schools - practical training, accompanied driving, special focus on young drivers);

- Increasing the enforcement of road rules (cross-border exchange of information, road safety campaigns, and on-board technologies to assist enforcement, such as Alcolock);

- safer road infrastructure (the highest number of fatal accidents occurs on rural and urban roads) and standards for the road traffic infrastructure;

- Safer vehicles (“cooperative systems” involving vehicle-environment-human interaction, environmental impact);

- The use of modern technologies to increase road safety (ITS, V2V, V2I, I2I, ADAS, eCall). Despite their positive contribution to road safety, the development of ITS, in particular on-board systems and nomadic devices, raises a number of safety-related issues (distraction, impact on training, etc.) which will require further consideration;

- Improving emergency and post-injury services;

- Protecting vulnerable road users (such as pedestrians, children, senior citizens, motorcyclists, cyclists, and moped riders). 
The document does not refer to any examinations in terms of traffic psychology, the assessment of psychological eligibility for driving, or the work of traffic psychologists in general.

The 2030 Road Traffic Vision for the Czech Republic (Technologická platforma silniční doprava, 2010) articulates the following safety issues as those of key importance for the period until 2030:

- The high rate of accidents involving children;

- The high rate of accidents involving inexperienced drivers;

- The ageing of drivers and other road users;

- The growing number of motorcyclists and their risk-taking behaviour;

- Increasing aggression among drivers (overtaking, speeding);

- Driving under the influence of alcohol and other drugs;

- Road users' low sense of responsibility for their (hazardous, aggressive) behaviour;

- Fatigue;

- Information overload;

- The growing risk posed to vulnerable road users (such as pedestrians and cyclists);

- The insufficient development of road infrastructure;

- The insufficient implementation of road infrastructure management tools;

- The deterioration of road surface adhesion characteristics (as a result of poor maintenance, inappropriate maintenance technologies, enormous heavy vehicle traffic, etc.);

- The disproportion between speed limits and the road arrangement and geometry;

- The growing differences between the vehicles in use, which mostly applies to passenger cars (age, gross weight, ADAS equipment).

The numbers of professional drivers with appropriate training dropped with the abolition of compulsory military service. Inadequate training of professional drivers in road safety issues has also been a problem. While the ageing of the population generally poses a relatively significant risk in terms of road safety, it is a particularly pressing issue among professional drivers.

A lifelong education scheme for road users is planned to be introduced by 2030 . This measure should involve not only a legal framework but also practical implications, including dramatically stricter requirements for obtaining different driving licences. Changes in the categorisation of driving licences and the harmonisation of the licensing procedures for drivers across Europe can also be expected.

Particularly in public and corporate transportation, driving under the influence of alcohol and other psychoactive substances should be largely eliminated by the use of technical devices (such as Alcolock) which make it impossible to start the vehicle if a driver is under the influence of a psychoactive substance. The EU-promoted process concerning legislative measures aimed at restricting drink driving can be expected to develop. The member states continue to reduce their general BAC limits for driving and consider introducing zero limits for specific groups of drivers (such as professional and novice drivers).

The upcoming decades are expected to experience rapid advances in on-board technologies that will register and react to the driver's excessive fatigue while the car is in motion. In addition, legislative changes will be adopted in order to restrict non-stop driving for other drivers too, especially those of company cars.

The growing mobility and constrained capacities of the available road infrastructure may exert pressure for drivers to be provided with additional, more up-to-date and, therefore, more frequent information. It is assumed that drivers will respond to such information immediately by adjusting their current speed, as well as reconsidering their choice of route. Drivers 
are also increasingly distracted by a number of information sources which are not directly associated with road traffic and by various information and entertainment devices used by passengers in their cars. This current and prospective growth in the amount of information should be studied in terms of its impact on road safety.

The 2011-2020 National Road Safety Strategy of the Czech Republic, a document of the Ministry of Transport (Ministerstvo dopravy, 2012), lays down the objectives, general principles, and proposals concerning specific measures aimed at a major decrease in the rate of road accidents in the Czech Republic. The main goal is to reduce the level of road fatalities to the European average by 2020, as well as to reduce the number of severely injured by $40 \%$ in comparison to the year 2009. While in 2011 the average number of fatalities in the EU countries was 61 (per million inhabitants), in the Czech Republic it was 73. The highest figure was recorded in Poland (109), the lowest in the United Kingdom (32), Sweden (33), and the Netherlands (33). The strategy was endorsed by virtue of the Resolution of the Government of the Czech Republic No. 599, dated 10 August 2011.

The strategic objective of the National Strategy reflects the European one as set out by the European Commission, specifically to reduce the number of road fatalities within the European Union by half in the period 2010-2020. According to the European objective as declared, the number of deaths should drop by half, i.e. from approximately 70 fatalities per million inhabitants at present to about 35 in 2020. The countries that are currently drawing near to that level include Sweden, the Netherlands, and the United Kingdom. The Czech Republic will have to cut the annual number of people killed in road accidents by an average of 5.5\% to reach this goal. In aggregate, it implies the reduction of the number of fatalities by approximately $60 \%$ in comparison to 2009 , i.e. to 360 people.

The strategy is underpinned by the Vision Zero approach. It proclaims that every traffic accident that results in the loss of a human life or a serious injury should be regarded as a structural failure of society as a whole, not an individual's error. From a medium-term point of view, it is undoubtedly useful to determine goals involving a specific reduction in the number of casualties and define targeted activities and measures that facilitate the accomplishment of such goals. Nevertheless, the ultimate ideal should be the state of no fatalities at all.

\section{THE NOTION OF VISION ZERO}

The Vision Zero initiative was first presented in 1997 by its author, Prof. Kare Rumar of Sweden, as a programme of a long-term development of the consequences of traffic accidents in Sweden. In 2001 this vision was also embraced by the European Union and adopted as its goal.

The idea of the vision is very simple: "We cannot reconcile ourselves to the fact of actually planning the toll we are willing to pay for the development of society in terms of road traffic," and if this is what exists today, we cannot reconcile ourselves to it but must do what we can to cause these numbers to drop all the way down to zero levels (Anderson et al., 1997).

The objective is to achieve a progressive decline in the number of deaths and injuries in road traffic. A "progressive decline" implies the quest for zero fatalities and zero injuries within the traffic system. This objective should be accomplished with the lowest social and economic costs possible, which will be impossible without effective requirements, economic limitations, and the application of an ethical rule: as many people as possible must be “saved” using available resources (Kopits \& Kropper, 2003). 
If we wish to change the road safety situation, we must stop considering road fatalities to be although widely accepted - a side-effect of the traffic system which is an inevitable means of the pursuit of social prosperity.

The task of achieving no road casualties can be interpreted as an ethical statement rather than a specific working goal. Nonetheless, it is a vision that should be gradually fulfilled. The resources that may be used in pursuing Vision Zero are already available, but their application is a political rather than a technical issue (OECD, 1990).

\section{THE ROLE OF PSYCHOLOGY AND TRAFFIC PSYCHOLOGY IN FULFILLING THE VISION}

Vision Zero is based on the notion that the parameters of the traffic system must be determined at all times by those individuals who show the greatest vulnerability and exposure to harm. The system should prevent any failure within such a system from leading to consequences that no longer represent acceptable harm to the health of an individual (Tingvall, 1998).

Where the level of resistance may be exceeded, the level of exposure to harm must be reduced to such a degree as to make it possible for everybody to survive until a safety problem has been solved. If we cannot guarantee, for example, that everybody uses safety belts, the exposure to harm must be reduced to the point where a person who is not using safety belts avoids physical harm. Roads should be constructed on the basis of the same assumption. Maximum speed limits should be determined with a view to the safety parameters of the road in such a way as to ensure that a driver avoids harm to their health even if they run off the road (Tingvall, 2007).

The steps to fulfilling Vision Zero are as follows:

- Identify the individuals and the types of behaviour for which the traffic system is intended;

- Define the acceptable harm to the health of an individual within the system;

- Identify the individuals who show the greatest vulnerability and exposure to harm;

- Use the definitions above to construct the system at all times;

- Define the types of errors which fall below the limits of acceptable tolerance for system failures;

- Define the individuals and the types of behaviour which will be excluded from traffic;

- Describe the procedure used to exclude the individuals and the types of behaviour that need to be excluded from the system;

- Define the relationship between any external harm and unacceptable harm to health within the system (harm resistance curve);

- Develop measures to control, prevent, and ensure protection from external harm in such a way as to ensure that tolerance for harm is never below the level of exposure to harm.

The designers of the Vision Zero system include the government, both governmental and nongovernmental organisations, organisations responsible for the construction of roads and other traffic infrastructure, manufacturers of cars and car equipment, and any other entities who are responsible for the design of the system and who manage and monitor road users' behaviour, including traffic psychologists. All the above must be committed to making every effort to achieve the maximum safety of the system. It is vital that the public will also become involved in the process of the continuous enhancement of road safety (Tingvall et al., 1996). 
The system must always be constructed in such a way as to reflect the needs of those with the least protection, the worst equipment, and the lowest level of education. For the designers of the system, such criteria outline a category of people who should receive priority attention. The designers of the system are "making a deal" with road users: if the road users respect the legal limits, the designers guarantee that they and their families can use the system and survive.

Today road users may comply with the legal regulations and still be injured or killed. Naturally, this is hardly supportive of law-abiding behaviour. We can assume, nevertheless, that people will accept restrictions on their personal freedoms in exchange for having their lives guaranteed.

People, with their needs, limitations, willpower, abilities, standards, experience, responsibilities, and obligations, remain the key road safety factor. As it is necessary to develop an advanced, fully forgiving traffic system, the responsibilities and obligations on the part of the system designers should also be underlined. The traffic system should be conceived in such a way as to ensure that human errors and their consequences do not result in death or permanent disability. And that is the responsibility of the designers of the system.

In view of the fact that people make mistakes and always will, the strategy cannot rely on road safety issues being solved by eliminating human error. Making mistakes and using new opportunities are the preconditions for human development and survival.

It is human error with grave consequences, however, that must be eliminated. An instant loss of concentration while driving on a rural road must not lead to a collision with another motor vehicle or run off the road and cause physical harm or injury ("forgiveness" may be realised in the form of the V2V collision avoidance system).

In terms of psychology and traffic psychology, the pursuit of Vision Zero should include the following tasks:

- Provide other system designers with evidence-based information about people's behaviour in traffic:

- identify the types of mistakes that drivers and other participants in the traffic system make;

- define general psychological conclusions explaining why people make such mistakes on roads;

- define the effects of such mistakes on the traffic system;

- define measures to prevent such mistakes;

- Define the methods and resources needed to enhance the self-awareness of drivers and other people who are active within the traffic environment;

- Define the methods and resources needed to provide road users with feedback concerning the safety of their behaviour in traffic;

- Provide other system designers with clear information about road users' cognitive and performance assets and limitations;

- Define procedures for work with the public in order to enhance responsible behaviour (in liaison with other fields, such as sociology);

- Define psychology-specific exclusion criteria for people's being allowed to enter different modes of the traffic system (driver - according to the type of the vehicle, professional driver, etc.) and make subsequent assessments;

- Define criteria and requirements (in terms of psychology) for excluding people from the traffic system, as well as for allowing them to re-enter it;

- Define procedures for lifelong education and training for all the people involved in the traffic system (in liaison with education professionals). 
At present there are tendencies to overestimate the impact of psychological eligibility for driving and the results of assessments in terms of traffic psychology on the safety of the traffic system in general and its safety as expressed by the number of deaths and injuries. There is not enough scientific evidence to show what exactly affects the road accident rate and the number of people who are killed or sustain injuries in traffic accidents (Tingvall et al., 1997).

The most relevant indicator of the degree of safe behaviour of drivers and other people participating in the road traffic system is the number of accidents (with regard to the legal definitions of accidents applied in different countries) rather than the number of fatalities (Belin et al., 1997), as it is probably the safety performance of the cars, road structure, and the traffic environment that has the greatest impact on the number of road fatalities. Hence, the key factor in pursuing Visio Zero is the construction of the traffic system rather than the elimination of human error.

When assessing psychological aptitude to drive, we now knowingly accept the probability of the subject's future failure within the traffic system. We measure the probability of failure without being able to define the causes and effects.

Assessment in terms of traffic psychology and the examination of psychological aptitude to drive should be defined within the Vision Zero approach as the minimum requirement for psychological eligibility that an individual must comply with for a given transport mode to be allowed to enter the system (exclusion criteria). The definitions of mistakes which may occur in the testee's prospective behaviour (and which are admissible because the system can absorb them) must also be an integral part of the notion of the assessment of psychological competence.

\section{CONCLUSION}

The very nature of human behaviour makes it impossible to make $100 \%$ predictions. Nevertheless, we can get close by means of effective feedback used for assessing psychological aptitude (this involves the establishment of a clear linkage between the subject, the type of mistake he or she has made, the study methods, and the conclusion that has been drawn). This approach should be used for making ongoing modifications of the definitions of exclusion criteria for the individual modes of transportation, as well as making them more rigorous. When combined with other forgiving components of the traffic system, Vision Zero may be fulfilled even if one allows for the imperfect predictability of human behaviour and the fact that people will always make mistakes.

We can also perceive the issue as a choice between a liberal attitude to mobility and the promotion of public health.

Ethical principles and the principles striving to fulfil Vision Zero must be preferred to individuals' and groups' particular interests, even under free market conditions. The public health interests must come first, and the government must be the patron of the efforts to assert such interests.

\section{REFERENCES}

Anderson, R. W. G., McLean, A. J., Farmer, M. J. B., Lee, B. H., Brooks, C. G., 1997. Vehicle travel speeds and the incidence of fatal pedestrian crashes. Accident Analysis and Prevention, 29 (5), pp. 667-674. 
Belin, M., Å., Johansson, R., Lindberg, J., Tingvall, C., 1997. The Vision Zero and its consequences. In Proceedings of the 4th International Conference on Safety and Environment in the 21st Century. Tel Aviv (Israel), Berlin (Germany), pp. 1-14.

European Commission, 2010. Směrem k evropskému prostoru bezpečnosti silničního provozu: směry politiky v oblasti bezpečnosti silničního provozu v letech 2011 - 2020. Sdèlení komise Evropskému parlamentu, Radě, Evropskému hospodářskému a sociálnímu výboru a výboru regionů [online]. [cited 2012-10-14]. Retrieved from: http://ec.europa.eu/transport/road_safety/pdf/com_20072010_cs.pdf (in Czech)

Kopits, E., Kropper, M., 2003. Traffic fatalities and economic growth. World Bank Policy Research Working Paper 3035.

Ministerstvo dopravy, 2012. Národní strategie bezpečnosti silničního provozu ČR 2011 2020 [online]. [cited 2012-10-14]. Retrieved from: http://www.ibesip.cz/data/web/ soubory/nsbsp-2011-2020-formatovani-ii.pdf (in Czech)

OECD, 1990. Behavioural Adaptations to Changes in the Road Transport System. Paris: OECD, Road Research Group.

Sheller, M., Urry, J., 2006. The new mobilities paradigm. Environment and Planning A, 38 (2), pp. 207-226.

Technologická platforma silniční doprava, 2010. Vize silniční dopravy v roce 2030 v ČR [online]. [cited 2012-10-14]. Retrieved from: http://www.tpsd-ertrac.cz/file/vize-silnicnidopravy-v-roce-2030-prac-skupina-2/ (in Czech)

Tingvall, C., 1998. The Swedish "VisionZero" and how parliamentary approval was obtained. Keynote address at Researchers Conference, NZ, and "Road Safety Summit". Canberra, pp. 57-61.

Tingvall, C., 2007. VisionZero and The New Paradigm for Road Safety (Emphasising Critical Lessons For Infrastructure Design). In Second UN Stakeholder Forum on Global Road Safety, Geneva.

Tingvall, C., Johansson, R., Lie, A., 1997. Traffic safety in planning - a multidimensional model for the zerovision. In Manuscript for Second Conference on Traffic, Mobility and Health, Brussels.

Tingvall, C., Johansson, R., Stenborg, L., Lie, A., 1996. How to reach the non-fatality road transport system. Presented and commented by Michael Griffiths, Road Transport Authority New South Wales. In Third International Injury Conference in Melbourne. 